\title{
An Undergraduate Design Experience in Digital Logic Design Course of Special Purpose Arithmetic Logic Unit Using Multisim, Ultiboard and Print Circuit Board
}

\author{
Qasem Abu Al-Haija ${ }^{1}$, Hasan Al-Amri ${ }^{1}$, Mohamed Al-Nashri ${ }^{1} \&$ Sultan Al-Muhaisen ${ }^{1}$ \\ ${ }^{1}$ College of Engineering, King Faisal University, Alhasa, Saudi Arabia \\ Correspondence: Qasem Abu Al-Haija, College of Engineering, Electrical Engineering Department, King Faisal \\ University, P. O. Box 380, Alhasa 31982, Saudi Arabia. Tel: 966-3589-5400. E-mail: qalhaija@kfu.edu.sa
}

Received: January 22, 2013 Accepted: January 29, 2013 Online Published: February 4, 2013

doi:10.5539/ies.v6n3p116 URL: http://dx.doi.org/10.5539/ies.v6n3p116

The research is financed by (College of Engineering, King Faisal University)

\begin{abstract}
Project-Based Curriculum (PBC) is considered one of the most powerful methods in the engineering education where each course or courses-cluster is assigned a design project which considers a series of inter-related concepts that have been shown theoretically for the students. Using this approach, the student will gain the required knowledge in an atmosphere of groups of teams where students can experience and learn the most needed inquiry, research tools and skills, teamwork skills, leadership skills, accountability, communication skills, interdisciplinary experience, curiosity, planning skills, critical thinking, and problem-solving skills. In this article, an undergraduate design experience in digital logic design course of special purpose arithmetic logic unit using Multisim, Y-0010/0020 Experiment Sets and Ulti-Board Kit is presented as an integral part of several electrical engineering courses throughout the curriculum at King Faisal University. The project was very beneficial in assessing the student outcomes a, $\mathrm{c}, \mathrm{d}$, e and $\mathrm{k}$ which introduced by ABET accreditation criteria.
\end{abstract}

Keywords: KFU, ABET, Project-Based Curriculum, ALU, Multisim, Ultiboard, Y-0010/0020 experiment sets

\section{Introduction}

Design is widely considered to be the central activity of engineering education. It has also long been said that engineering programs should graduate engineers who can design effective solutions to meet social needs (CLIVE, ALICE, OZGUR, DANIEL, LARRY, 2005). Any successful engineering curriculum must provide an integrated engineering design in its curriculum.

The college of engineering at KFU has implemented a project-based curriculum where engineering design is considered as an integral part of several engineering courses or course-clusters. In addition, to meet the requirements of $\mathrm{ABET}$ accreditation criteria which requires that an appropriate educational program outcomes are met (Hosni \& Abdulaziz, 2012), the electrical engineering academic staff at KFU have integrated engineering design throughout the curriculum, spanning freshman, sophomore, junior and senior level courses.

Digital logic design is a very important subject and has long been an essential part of electrical and computer engineering curriculum all over the world. All digital systems are founded on logic design. Logic design transforms algorithms and processes conceived by people into computing machines (M. Rafiquzzaman, 2005). A grasp of digital logic is crucial to the understanding of other basic elements of digital systems, including microprocessors. The arithmetic logic unit (ALU) is a combinatorial digital circuit that performs arithmetic (Add, Subtract, ...) and logical (AND, OR, NOT, ....) operations. The central processing unit (CPU) contains three main parts: Control Unit (CU), Registers, arithmetic logic unit (ALU). ALU is the heart of the CPU, since it performs arithmetic and logical operations. Most of a processor's operations are performed by one or more ALUs. An ALU loads data from input registers, an external Control Unit then tells ALU what operation to perform on that data, and then ALU stores its result into an output register. The Control Unit is responsible for moving the processed data between the registers, ALU and memory. Mathematician John von Neumann proposed ALU concept in 1945, when he was working on EDVAC (M. Rafiquzzaman, 2005). 
The advancement of engineering education in many ways depends on assessment. High-quality assessments can provide educators with information they can use to move the field forward. Inadequate or poorly constructed assessments can cause educators to pursue ineffective paths, resulting in the loss of time, money, and energy (Barbara, Barbara, and Ronald, 2005). This project was very useful in assessing the student outcome (a) an ability to apply knowledge of mathematics, science, and engineering, outcome (c) an ability to design a system, component, or process to meet desired needs, outcome (d) an ability to function on single and/or multidisciplinary teams, outcome (e) an ability to identify, formulate, and solve engineering problems and outcome (k) an ability to use the techniques, skills, and modern engineering tools necessary for engineering practice which introduced by ABET Engineering Accreditation Criterion 3: Program Outcomes and Assessment (ABET Engineering Accreditation Criteria, Criterion 3).

Presented in this article is an example of engineering design experience in an undergraduate digital logic design course. It presents a special purpose initial design of a 4-Bit ALU system that meets desired needs. Basic digital design principles such as the information representation and coding methods, base conversion, arithmetic and logic of binary and two's complement numbers, Boolean algebra and digital logic gates, design of combinational circuits, application of some MSI devices such as MUXes, decoders and adders, using Multisim to simulate and verify circuits, using Y-0010/0020 experiment sets to verify the modules of the design, and a white board, chips and wires to implement and build the system were employed in the analysis, leading to the initial design of this ALU system. This kind of experience serves to enhance the understanding of the various digital logic design concepts and principles.

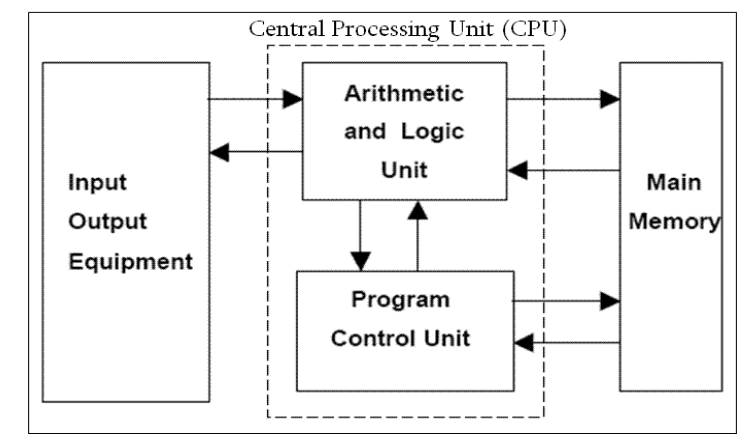

Figure 1. General Structure of Von Neumann Architecture

\subsection{Objectives}

A design project set for students of Electrical Engineering at KFU is discussed in this article. The objective of this project is to obtain a hardware design of an ALU system. This project is one of the requirements of the Digital Logic Design class. Digital Logic Design is an electrical engineering sophomore level course. This project is very comprehensive and requires the understanding of most digital logic design concepts that were covered in the course in order to obtain a successful design (M. Rafiquzzaman, 2005; Hosni \& Abdulaziz, 2012). The arithmetic logic units (ALUs) are basic building blocks for processors and many other application-specific circuits. In this project, a 4-bit ALU is built. When solving many real-world problems, you need to work from vague, possibly inconsistent, and informal specifications. This project provides an example. The desired function is described at a high level and most of the details are left to the designer (i.e. the student) to decide. In addition, the project is practicing students on decomposing a large problem into modules and testing a circuit that is too large to test exhaustively.

\subsection{System Specifications}

The top view of ALU to be designed in this project is shown in figure 2. This design has 11 inputs: two operands A and B each with four bits and three select bits S2, S1, and S0 to specify which of the eight functions that the ALU performs. Also, it has 6 outputs: F (the four bit result), Cout (the carry or borrow output), and ZF (Zero Detect) which is set to 1 if all bits in F are 0 . The ALU can only perform eight functions listed in the following table, table 1, Functions of ALU. 


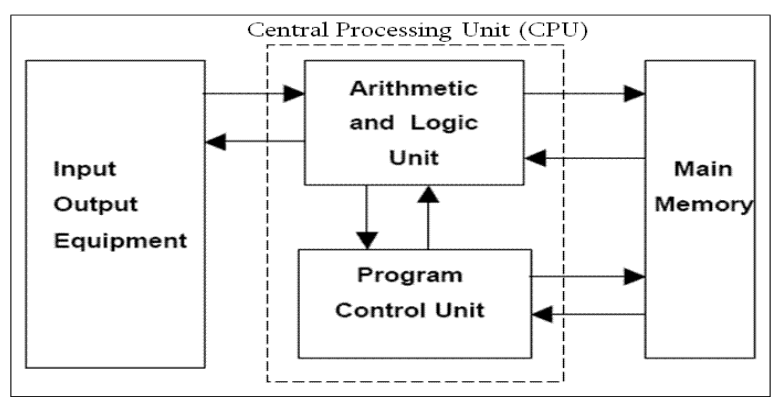

Figure 2. General Structure of Von Neumann Architecture

Table 1. Functions of ALU

\begin{tabular}{ll}
\hline Function & Output \\
\hline ADD & A + B \\
SUBTRACT & A - B \\
AND & A AND B (BITWISE AND) \\
OR & A OR B (BITWISE OR) \\
NAND & A NAND B (BITWISE NAND) \\
NOR & A NOR B (BITWISE NOR) \\
SetLessThan (SLT) & 0001 IF A $<$ B, OTHERWISE 0000 \\
SetGreaterThan (SGT) & 0001 IF A $>$ B, OTHERWISE 0000 \\
\hline
\end{tabular}

The logical functions (AND, OR, NAND, NOR) are all bitwise and Cout is irrelevant except for add and subtract. For SetLessThan and SetGreaterThan, the inputs should be treated as 4-biT. 2's complement numbers and the outputs should be correct for any valid inputs.

\section{Method}

\subsection{Design Methodology}

The system to be designed in this type of projects; a "Divide \& Conquer" method is used to decompose the system into smaller modules which designed, tested and verified then re-combined together in order to form the complete system. The proposed methodology throughout this project consists of the following major steps:

- Specify and design: Decompose the functionality of the ALU into modules as shown in figure 3, and determine how these might be integrated in a single circuit. Write a specification that assigns codes to the required functions, based in part on how these modules fit together. Draw a block diagram.

- Implement and test circuit in Multisim: Make sure you have a complete and well-tested circuit that implements your design.

- Implement the circuit in hardware: The implementation part should match your Multisim design, and so should operate using the select codes in your specification.

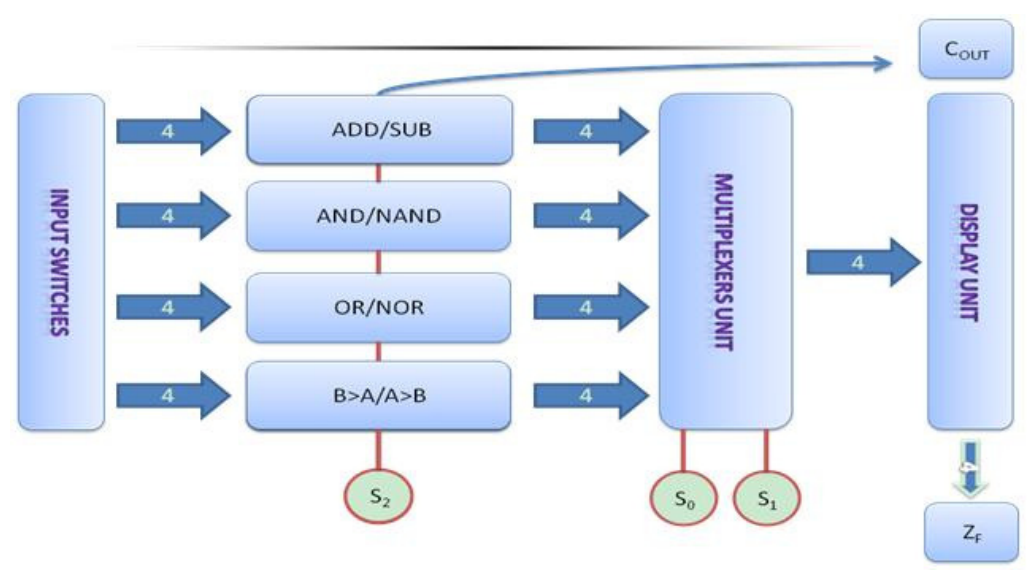

Figure 3. Modules of ALU 


\subsection{System Requirements}

The importance of this project lies in exposing students to one of the electrical engineering problems that enables the students to use what they learned so far through the digital logic design course (EE231) and digital logic design lab (EE232) by using several course components such as number representation systems, Boolean algebra, Logic gates and chips, Karnaugh maps as well as combinational logic design which can be mapped to several course and student outcomes.

Table 2. Tools and Equipment

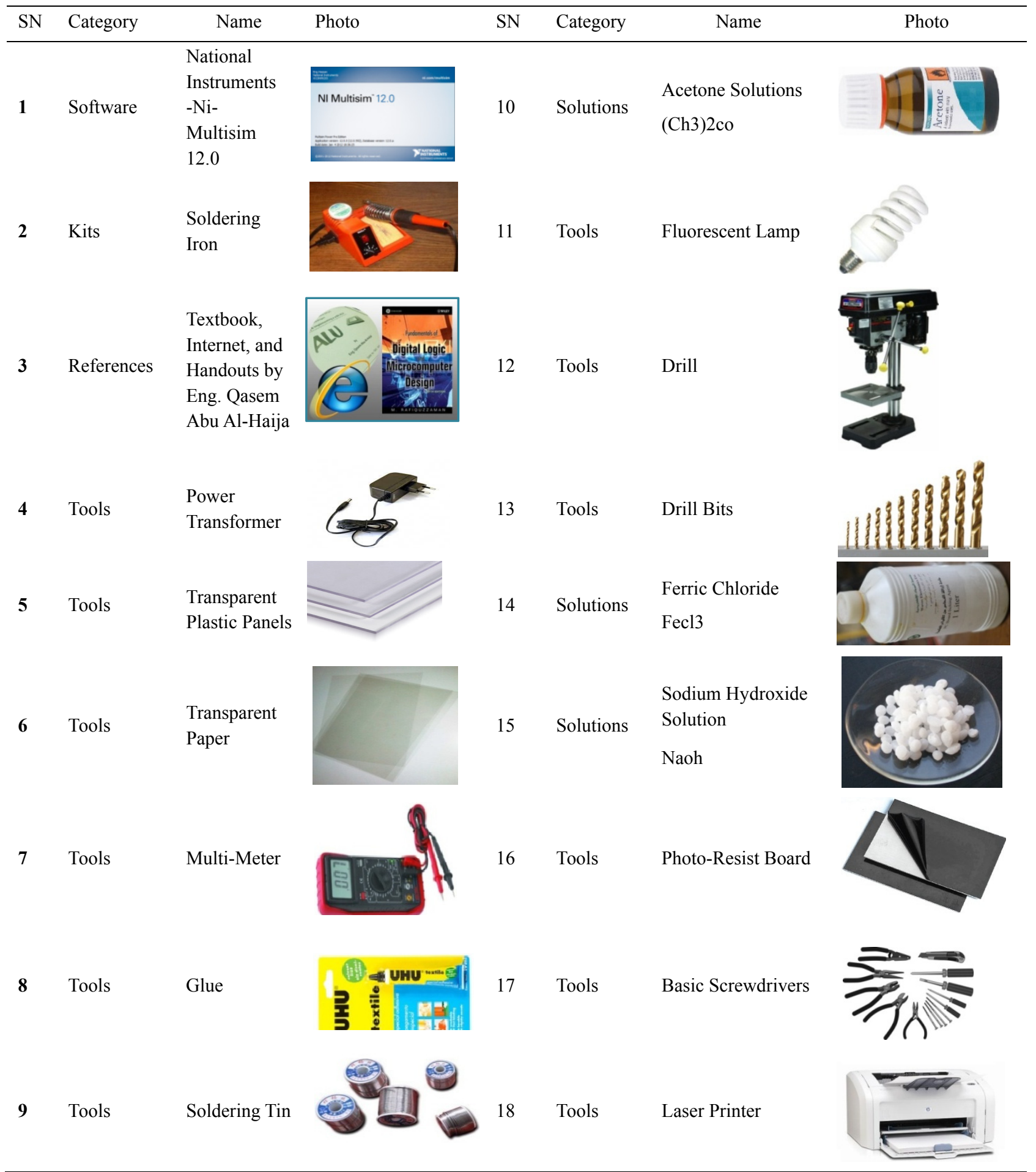


The system to be designed, student should be able to study and determine the engineering tools that are required to accomplish the target design as well as the problem solving techniques which offered by the theoretical background learned in the course. This project requires the students to be exposed to many engineering and technical tools were listed in table 2, Tools and Equipment.

\section{Results and Discussion}

\subsection{Multisim Design Simulation}

The analytical study was simulated via Multisim software. NI Multisim (formerly MultiSIM) (National Instruments Website, Multisim 12.0) is an electronic schematic capture and simulation program which is part of a suite of circuit design programs, along with NI Ultiboard. Multisim is one of the few circuit design programs to employ the original Berkeley SPICE based software simulation. Multisim was originally created by a company named Electronics Workbench, which is now a division of National Instruments. Multisim includes microcontroller simulation (formerly known as MultiMCU), as well as integrated import and export features to the Printed Circuit Board layout software in the suite, NI Ultiboard. Multisim is widely used in academia and industry for circuits education, electronic schematic design and SPICE simulation.

Multisim (National Instruments Website, Multisim 12.0) was originally called Electronics Workbench and created by a company called Interactive Image Technologies. At the time it was mainly used as an educational tool to teach electronics technician and electronics engineering programs in colleges and universities. National Instruments has maintained this educational legacy, with a specific version of Multisim with features developed for teaching electronics. In 1999, Multisim was integrated with Ulti-board after the original company merged with Ultimate Technology, a PCB layout software company. In 2005, Interactive Image Technologies was acquired by National Instruments Electronics Workbench Group and Multisim was renamed to NI Multisim.

In this project; Divide-\&-Conquer problem solving technique were used where each system module was designed and tested individually which thereafter combined to form the complete system design. Multisim design/simulation included the following gates/IC's:

- A full Adder (74LS83).

- $\quad$ 2-inputs XOR Gate (74LS86).

- 2 Inputs-AND Gate (74LS08).

- 3/4-Inputs-AND Gate (It can be gotten by cascading 2-Input AND Gate).

- 2 inputs-OR Gate(74LS32).

- 3/4-input Nor Gate.

- Inverter (74LS04)

- 7-Stage Binary Counter (4024BD_5V)

- Data Selector/Mux (74153)

- Quad Analog Switch (4066BD_5V)

- Seven Segment Display.

- LEDs and Digital Sources.

- 1-of-10 Decoder(4028BD_5V).

- Key for toggle.

- VDD Source

The complete system design simulation on Multisim (Qasem Abu Al-Haija, 2012; National Instruments Website, Multisim 12.0) is shown in figure 4. 


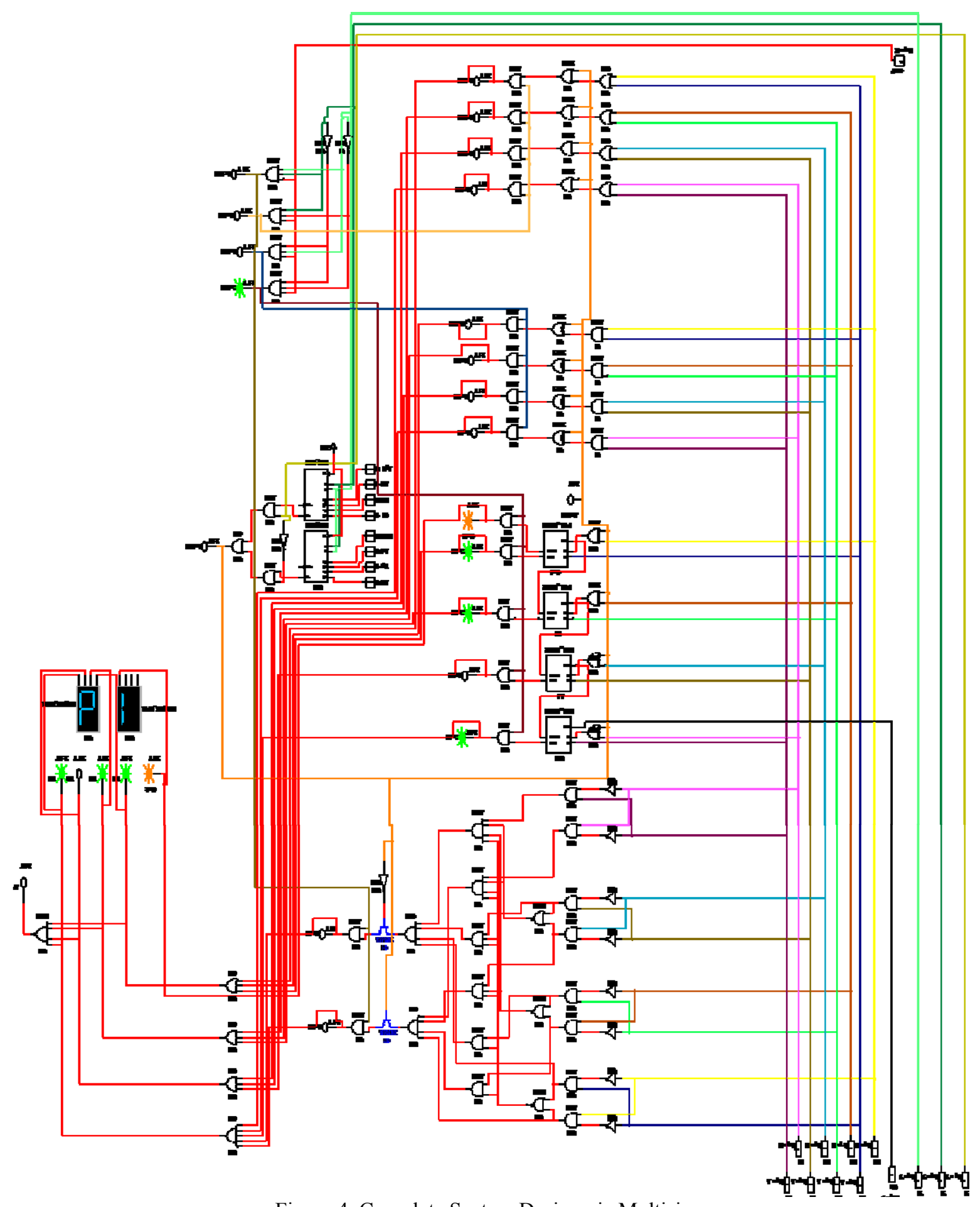

Figure 4. Complete System Design via Multisim

\subsection{Hardware Implementation \& Verification}

The hardware design implementation using Ultiboard kit included several gates, IC's and tools shown in table 4, Implementation Gates and IC's. 
Table 4. Implementation Gates and IC's for ALU

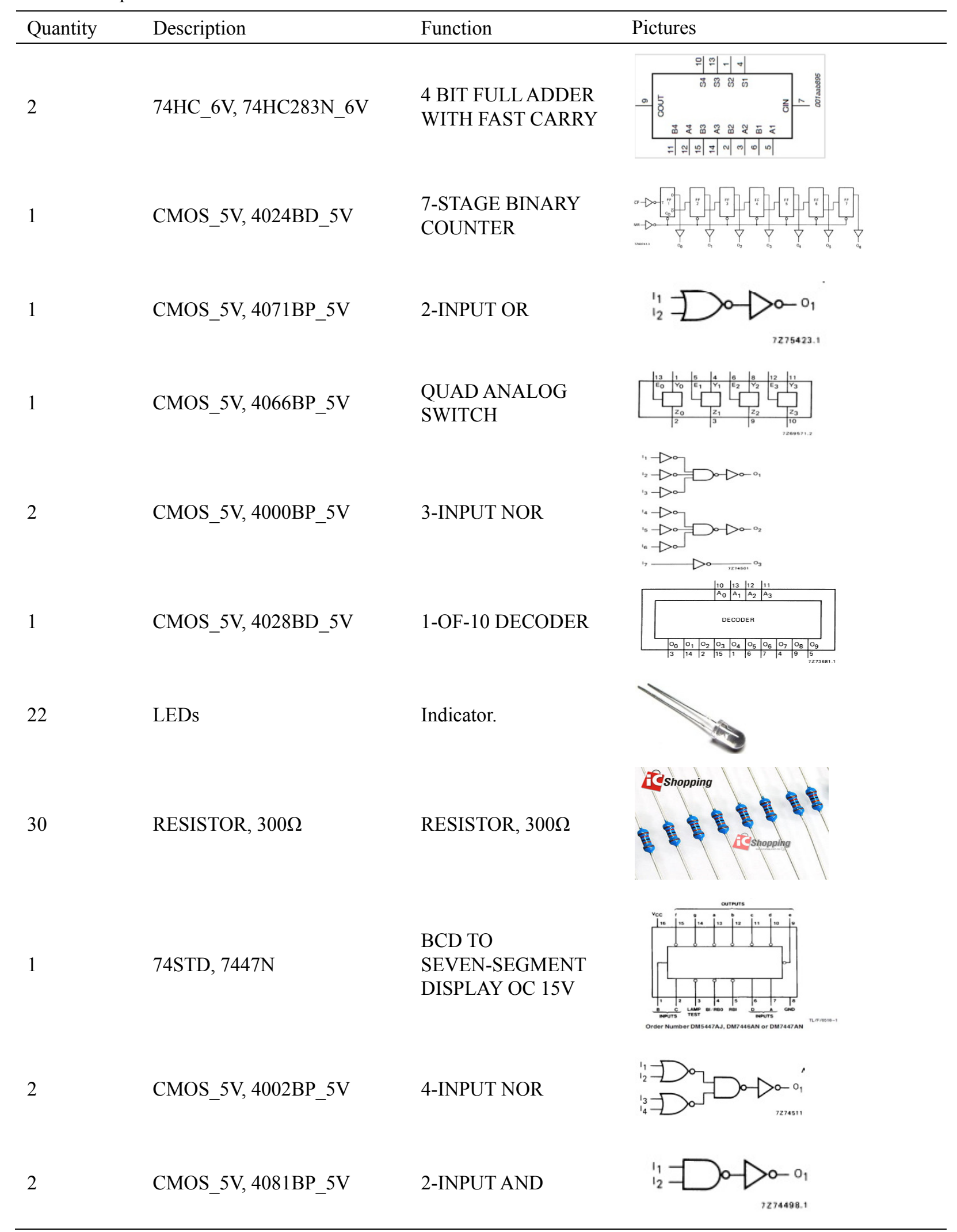


8

RESISTOR, $470 \Omega$

1

8

4

3

1
SWITCH, PB_DPST

SWITCH-ON-OFF

CMOS_5V, 4512BD_5V

CMOS_5V, 4009BCP_5V

SEVEN_SEG_DECIMAL_C
RESISTOR, $470 \Omega$

Switch Pb.Type DPST

SWITCH

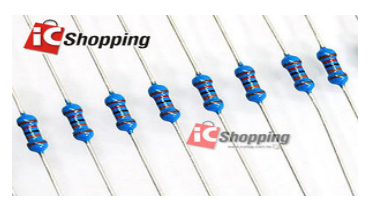

DATA

SELECTOR/MUX
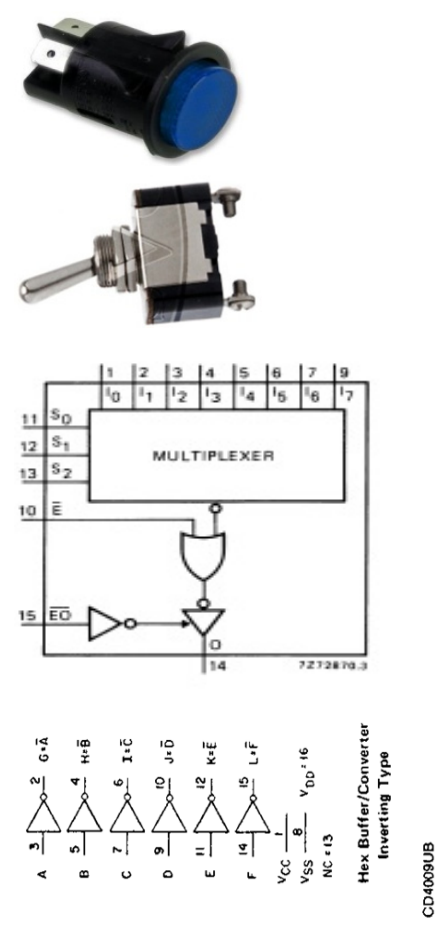

Display the

hexadecimal numbers.

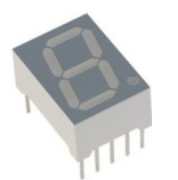

In order to implement the simulated design using the Ulti-board (Online datasheet source for electronic components and semiconductors) and chips, several steps were applied to get the final hardware board functioning as an ALU, as following:

1. Step 1: Save Multisim simulation project and then convert it to Ultiboard file in order to make it readable for the second party on national instruments which is called NI-Ultiboard. NI Ulti-board (National Instruments Website, Multisim 12.0; Online datasheet source for electronic components and semiconductors) or formerly ULTI-board is an electronic Printed Circuit Board Layout program which is part of a suite of circuit design programs, along with NI Multisim. One of its major features is the Real Time Design Rule Check, a feature that was only offered on expensive work stations in the days when it was introduced. ULTI-board was originally created by a company named Ultimate Technology, which is now a subsidiary of National Instruments. Ulti-board includes a 3D PCB viewing mode, as well as integrated import and export features to the Schematic Capture and Simulation software in the suite, Multisim.

2. Step 2: Read the new project file using Ultiboard software then adjust the page size to fit the size of the Copper Printed Circuit Board. To avoid complexity, this step can be divided into 5 sub-steps:

a. Adjust the page size to fit the size of the copper board.

b. Organizing the components to have Less number of interlocking tracks as shown in figure 5 .

c. Connect the components by lines(tracks) as shown in figure 6 .

d. Save Ultiboard file and print out as reflection image to transparent paper as shown in figure 7.

3. Step 3: Transfer design to production, through the following steps:

a. Print tracks from transparent paper to photo-resist board (copper board) in dark room. This can be accomplished by using Fluorescent lamp(30W) and tape, as in shown in figure 8 . 
b. After exposure, the board is submerged in a developer(sodium hydroxide solution) in dark room. This can be accomplished by using sodium hydroxide solution and water as shown in figure 9.

c. Use ferric chloride and a Non-metallic bowl to remove the copper (etching process) on the board by ferric chloride, as shown in figure 10.

d. Use Fluorescent lamp and Drill (1-0.8mm) to pierce the board as shown in figure 11 .

e. Remove sensitive material residue by acetone solution.

f. Installing and Welding the components into the board by using Soldering Iron and Soldering Tin.

g. Installing the cover and illustrative texts using two transparent plastic panels, Glue, transparent paper and Printer. The final production is shown in figure 12.

4. Step 4: Connect device to source using power transformer $(5 \mathrm{~V} / 220 \mathrm{~V})$ and check its electrical functionality using Multimeter.

5 .

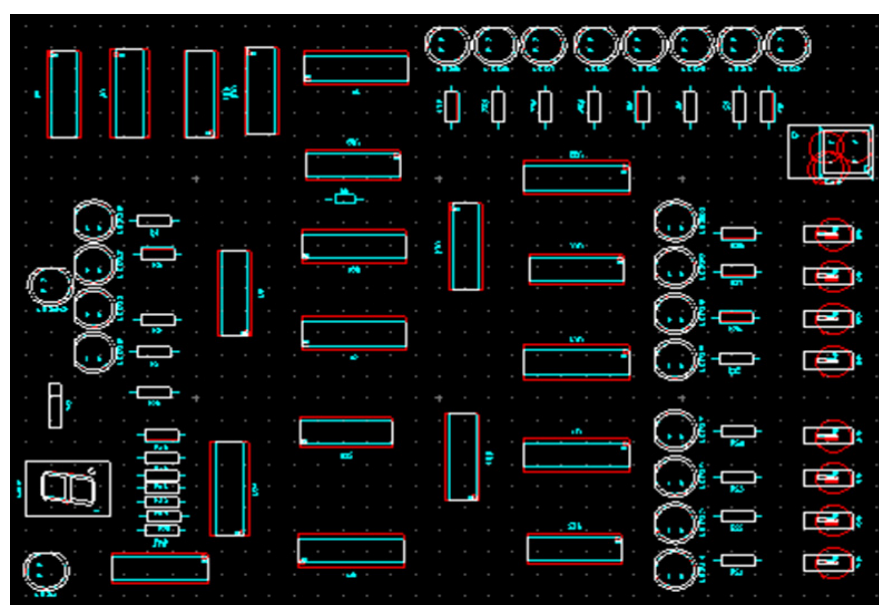

Figure 5. Organizing the components

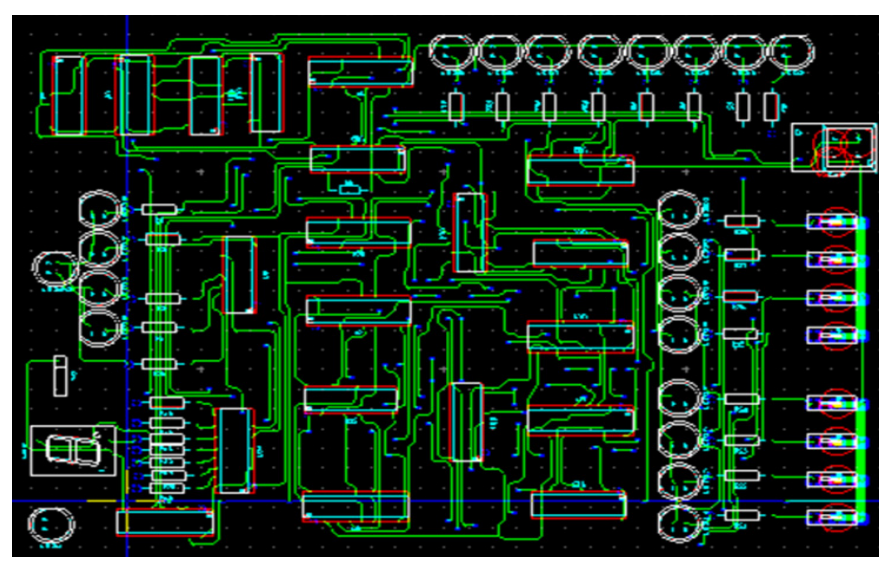

Figure 6. Organizing the components 


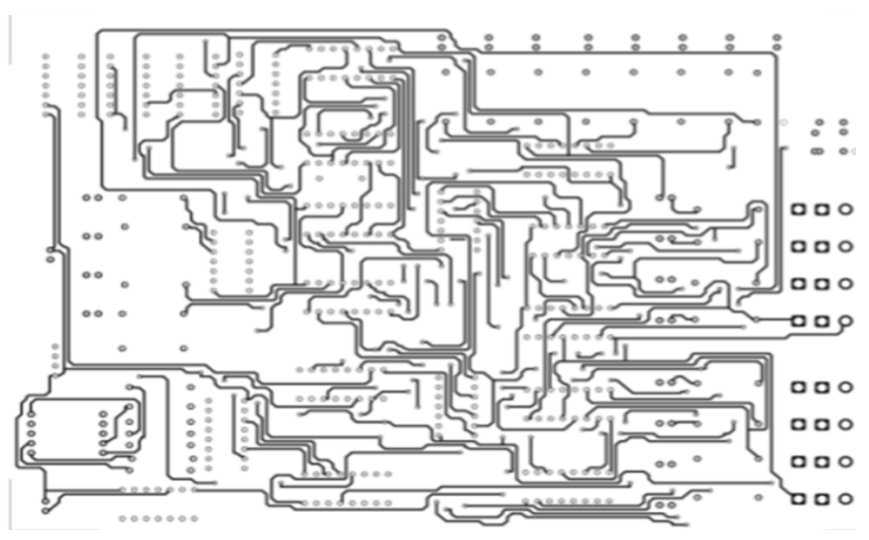

Figure 7. Reflection image on a transparent paper

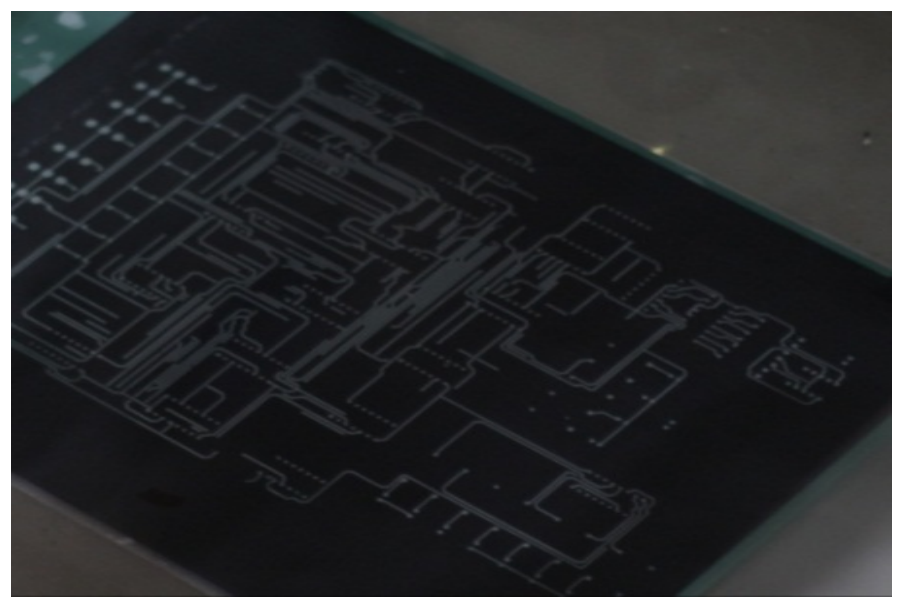

Figure 8. Printed tracks on photo-resist board

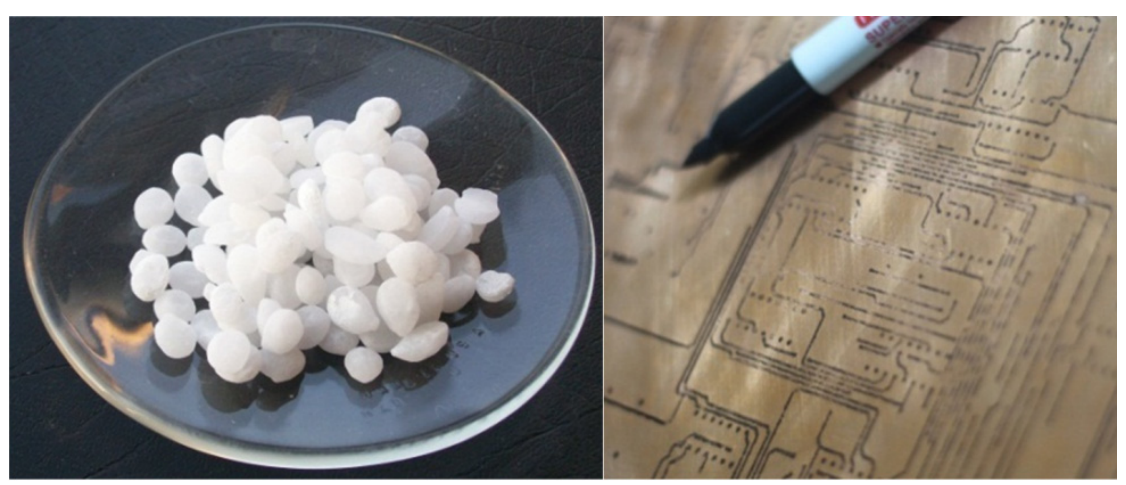

Figure 9. Using sodium hydroxide to develop the board, to be like the right picture 


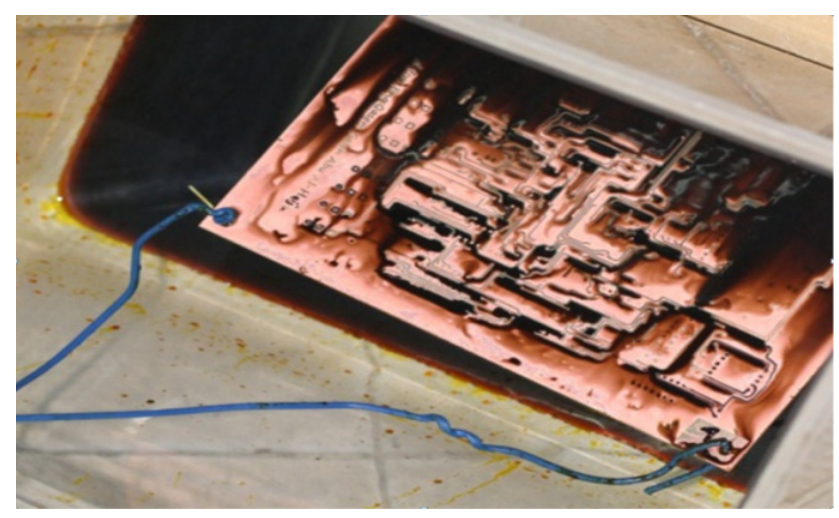

Figure 10. (etching process) Remove the unwanted copper from the board by using ferric chloride

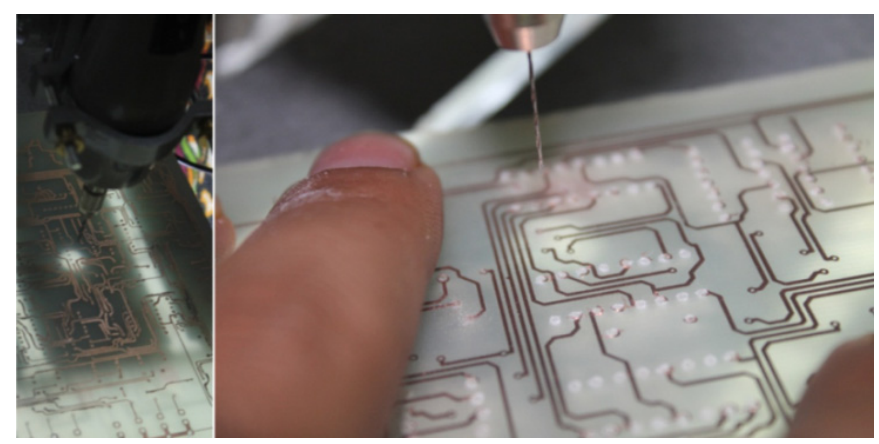

Figure 11. Piercing the board by the drill
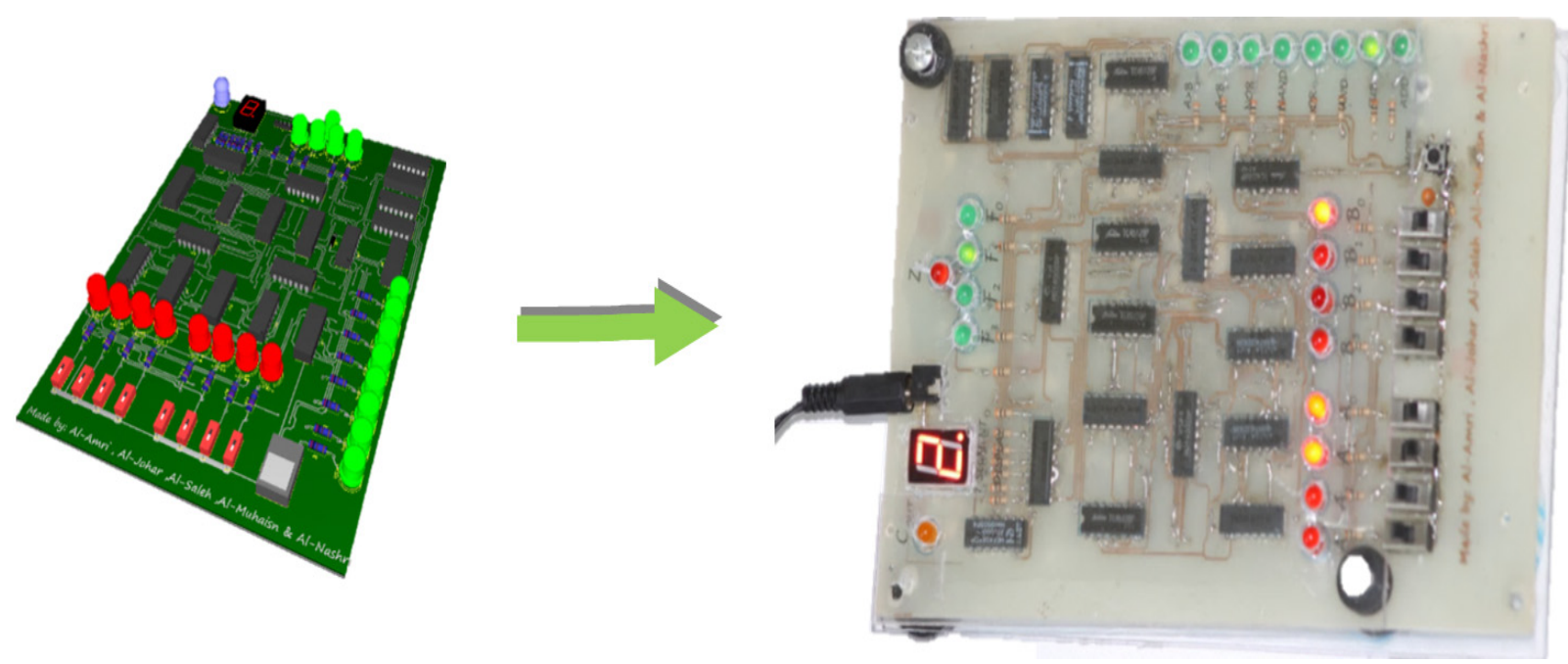

Figure 12. Hardware Implementation for the ALU

The design is verified using the truth table shown in table 5, Function Table for ALU (Truth Table), where its applied with real data to the Multisim simulation, the Printed Color Board and using the pre-designed 4-bit ALU provided by Y-0010/0020 Experiment Sets and shown in figure 13. 
Table 5. Function Table for ALU (Truth Table)

\begin{tabular}{llll}
\hline \multicolumn{2}{l}{ Selection Line } & Operations \\
\multicolumn{2}{l}{$\mathrm{S}_{2}$} & $\mathrm{~S}_{1} \mathrm{~S}_{0}$ & \\
\hline 0 & 0 & 0 & ADDER \\
0 & 0 & 1 & SUBTRACTOR \\
0 & 1 & 0 & SET LESS THAN \\
0 & 1 & 1 & SET GREATER THAN \\
1 & 0 & 0 & ORing \\
1 & 0 & 1 & NORing \\
1 & 1 & 0 & ANDing \\
1 & 1 & 1 & NANDing \\
\hline
\end{tabular}

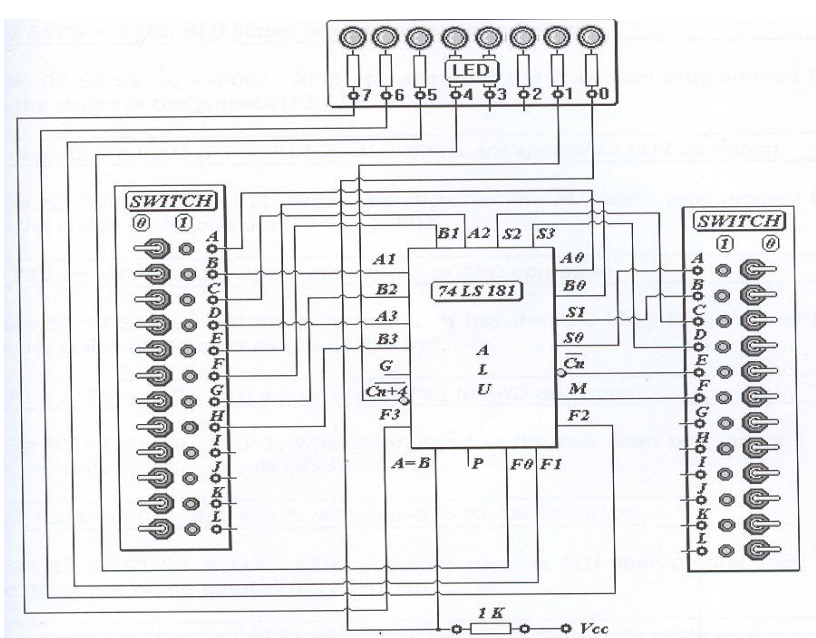

Figure 13. Pre-designed 4-bit ALU provided by Y-0010/0020 Experiment Sets

\subsection{Feedback of Student}

The Course learning outcomes (Qasem Abu Al-Haija, 2012) articulated by the course are as follows (as defined in the syllabus of the course):

CLO 1. An Ability to use number systems and their applications to digital systems design.

CLO 2. An Ability to apply the fundamentals of Boolean algebra to the logic design.

CLO 3. An Ability to use logic gates and their applications.

CLO 4. An Ability to design a combinational logic circuits.

CLO 5. An Ability to use flip flops and their applications in digital/logic circuits.

CLO 6. An Ability to design a sequential logic circuits.

CLO 7. Analyze and synthesize logic circuits.

The summary of the course learning outcomes survey conducted with students at the end of the course is given below in figure 14 .

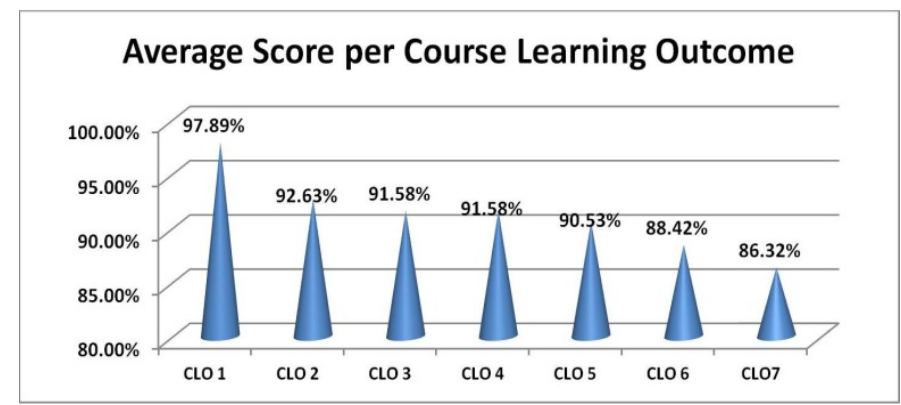

Figure 14. Indirect Assessment of course learning outcomes conducted by students 


\subsection{Project results of Students}

The project were evaluated through several assessment items: Presentation with Oral Exam, Report technical writing, Multisim Design Simulation, Hardware Design techniques, Design Synthesize and Verification, and Teamwork. The result of this examination design project is shown in table 5, Design project grades for group B.

Table 5. Design project grades for group B

\begin{tabular}{|c|c|c|c|c|c|c|}
\hline Student Name & $\begin{array}{l}\text { Presentation } \\
\text { with Oral } \\
\text { Exam } \\
(10 \%)\end{array}$ & $\begin{array}{l}\text { Report } \\
\text { technical } \\
\text { writing } \\
(20 \%)\end{array}$ & $\begin{array}{l}\text { Multisim } \\
\text { Design } \\
\text { Simulation } \\
(25 \%)\end{array}$ & $\begin{array}{l}\text { Hardware } \\
\text { Design } \\
\text { techniques } \\
(25 \%)\end{array}$ & $\begin{array}{l}\text { Design } \\
\text { Synthesize \& } \\
\text { Verification } \\
(10 \%)\end{array}$ & $\begin{array}{l}\text { Function } \\
\text { on team } \\
\text { work } \\
(10 \%)\end{array}$ \\
\hline Hasan Al-Amri & 9 & 18 & 25 & 23 & 10 & 10 \\
\hline Mohamed Al-Nasheri & 8.5 & 18 & 23 & 25 & 10 & 9 \\
\hline Sultan Al-Muhaisen & 8 & 18 & 23 & 21 & 10 & 9 \\
\hline
\end{tabular}

The Presentation with Oral Exam was evaluated using a rubric system that contains the items: organization, subject knowledge, graphics, mechanics, eye contact, elocution. Also the teamwork skills was evaluated using a rubric system that contains the items: appreciates the value of team work, listen and considers other point of views, cooperates with team members and contributes to team work, and Able to effectively coordinate tasks with other team members.

\section{Conclusions and Recommendations}

This article has discussed an example of engineering design as applied in the digital logic design course contexts according to the project-based learning pedagogy. The project involves an initial design of an ALU system based on a hardware-specific design that meets specified requirements. The project was very beneficial in assessing the student outcomes a, c, d, e and k which introduced by ABET accreditation criteria. This design project can be used to measure students' understanding of the various digital logic design concepts and principles normally covered in the undergraduate digital logic design course. The project was evaluated through several assessment items such as: Presentation with Oral Exam (10\%), Report technical writing (20\%), Multisim Design Simulation (25\%), Hardware Design techniques (25\%), Design Synthesize and Verification (10\%), and Teamwork (10\%).

\section{Acknowledgement}

Authors appreciate the publication support of College of Engineering at King Faisal University KFU-AL-AHSA. Special thanks due to Dr. Abdulmohsen Al-Arfaj, Dean of Engineering College for his support and encourage.

\section{References}

ABET Engineering Accreditation Criteria, Criterion 3, Program Outcomes and Assessment. Retrieved from http://www.abet.org

Barbara, M. O, Barbara, M. M., \& Ronald, L. M. (2005). Assessment in Engineering Education: Evolution, Approaches and Future Collaborations. Journal of Engineering Education, 94(1), 13-25. Retrieved from http://www.jee.org/2005/january/249.pdf

Clive, L. D., Alice, M. A., Ozgur E., Daniel, D. F., \& Larry, J. L. (2005). Engineering Design Thinking, Teaching, and Learning, Journal of Engineering Education, 94(1), 103-120. Retrieved from http://digitalcommons.olin.edu/cgi/viewcontent.cgi?article=1021\&context=mech_eng_pub

Hosni, I. A. M., \& Abdulaziz, A. A. (2012). Engineering design experience of an undergraduate thermodynamics course. World J. of Engng. and Technol. Educ., 10(1), 77-81. Retrieved from http://www.wiete.com.au/journals/WTE\&TE/Pages/Vol.10,\%20No.1\%20(2012)/12-12-Abu-Mulaweh-H.pd $\mathrm{f}$

M. Rafiquzzaman. (2005). Fundemetals of Digital Logic and Microcomputer Design (5th Ed.). John Wiley \& Sons, Inc.

National Instruments Website, Multisim 12.0. Retrieved from http://www.ni.com/multisim/

Online datasheet source for electronic components and semiconductors. Retrieved from http://www.datasheetcatalog.com

Qasem Abu Al-Haija. (2012). Handouts, Lecture notes and experiments sheets for Digital Logic Design course and Lab. Electrical Engineering Department, College of Engineering, King Faisal University. 